\title{
Die Gene der Urgrossmutter
}

\section{Adrian Ritter}

Freier Journalist

\author{
Pensioniert, aber nicht im Ruhestand: Der 66-jährige Chirurg Dominik Heim pendelt \\ für drei Jobs durch die Schweiz. Schon seine Urgrossmutter war eine engagierte \\ Schafferin: Marie Heim-Vögtlin, die erste Schweizer Ärztin.
}

Eigentlich könnte Dominik Heim jetzt nach der Pensionierung mal zurücklehnen. Aber das wäre nicht Dominik Heim. Und so treffe ich ihn Anfang Mai am Bahnhof Thun und wir nutzen die Zugfahrt nach Saanen für das Interview. Zwei Tage pro Woche behandelt der Allgemeinchirurg in der Thuner Privatklinik Hohmad Patientinnen und Patienten, die etwa unter Krampfadern und offenen Beinen leiden. Auch heute hat Dominik Heim Sprechstunde gehalten und ambulante Operationen vorgenommen. Am Abend hat er eine Besprechung im Medical Center Saanen-Gstaad. Zwei Wochenenden pro Monat arbeitet er in der Gemeinschaftspraxis mit. Und dann wäre da noch die dritte Arbeitsstelle: Als Versicherungsmediziner bei der SUVA in Luzern - ebenfalls mindestens zwei Tage pro Woche. So pendelt Dominik Heim seit eineinhalb Jahren von seinem Wohnort Frutigen im Berner Oberland aus regelmässig durch die Schweiz. Das Generalabonnement lohnt sich.

Bis zur «Pensionierung» war Dominik Heim im Spital Frutigen zwanzig Jahre als Chefarzt Chirurgie tätig gewesen. Entsprechend zählt zu seinen medizinischen Schwerpunkten neben Venenleiden auch die Unfallchirurgie - speziell Knochenbrüche. Hunderte von Ski- und Snowboardfahrern hat er behandelt. Wochenend- und Notfalldienst waren oft hektisch. «Im Vergleich dazu ist mein jetziges Leben geruhsam", sagt Heim lachend.

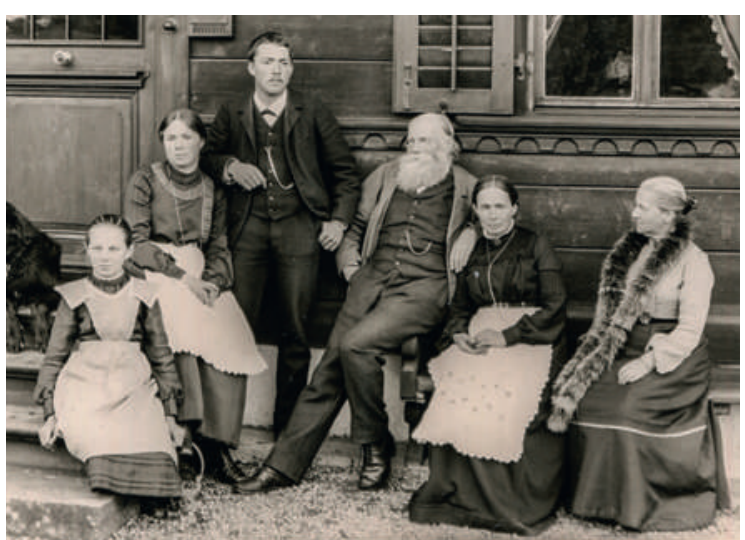

Von links: Hanneli Hundhausen, Helene Heim, Arnold Heim, Albert Heim, Marie Heim-Vögtlin, Sophie Heim.

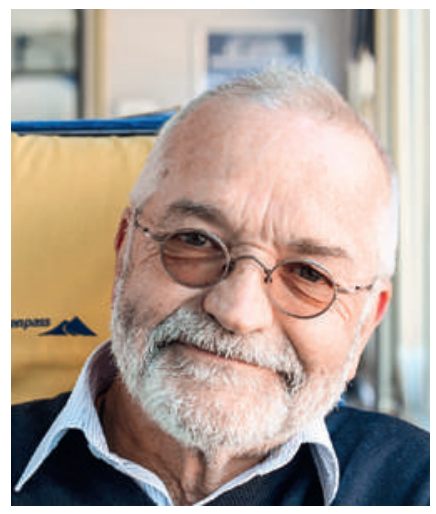

Kennt keine Langeweile: PD Dr. med. Dominik Heim, Urenkel der ersten Schweizer Ärztin Marie Heim-Vögtlin.

\section{Kampf ums Studium}

Trotzdem fragt man sich, woher der 66-Jährige die Energie für seinen vollen Terminkalender nimmt. Seine halbernste Erklärung: «Das sind wohl die Gene der Urgrossmutter, die ebenfalls eine engagierte Ärztin war.» Marie Heim-Vögtlin (1845-1916) brauchte auf ihrem beruflichen Weg damals in der Tat auch eine gehörige Portion Energie. Erst musste sie sich mit Hilfe des Vaters den Zugang zum Medizinstudium erkämpfen, dann galt es, sich als erste Schweizer Ärztin in der medizinischen Zunft zu beweisen. Es gelang der Gynäkologin erfolgreich.

Die Faszination für die Medizin blieb der Familie erhalten - sowohl bei Enkel Urs Heim wie bei den Urenkeln Dominik und Christof Heim. Christof Heim ist Generalsekretär der Schweizerischen Gesellschaft für Anästhesiologie und Reanimation (SGAR). Urs Heim und sein Sohn Dominik Heim wählten den Beruf des Chirurgen. Nach dem Medizinstudium in Basel und Freiburg war Dominik Heim an verschiedenen Spitälern in der Schweiz und in Grossbritannien tätig - und zwischendurch auch für Hilfswerke in Afrika und Asien unterwegs. Ab 1997 lehrte er zudem als Privatdozent an der Universität Basel. «Was mich an der Chirurgie fasziniert, ist das praktische, auch manuelle Tätigsein 


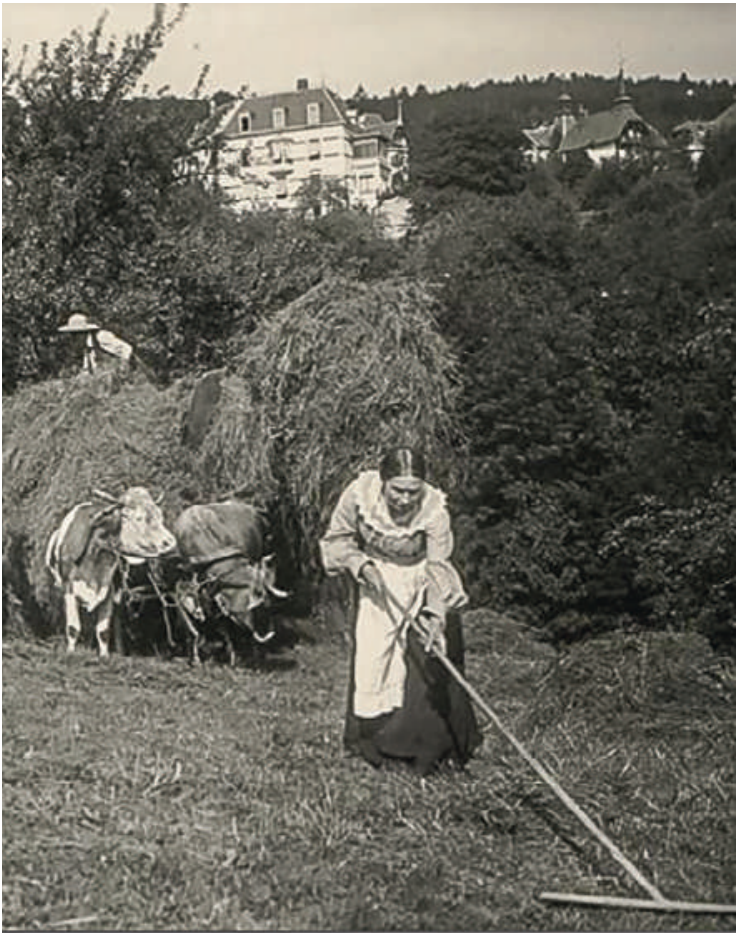

Marie Heim-Vögtlin beim Heuen.

und die oft schnell zu treffenden Entscheidungen», so Heim.

Im Gegensatz dazu schätzt er an seiner Arbeit als SUVAVersicherungsmediziner die intellektuelle Herausforderung. Als Gutachter landen unter anderem Einsprachen von Verunfallten gegen eine Verfügung der SUVA auf seinem Tisch: «Es ist eine Detektivarbeit, wenn ich etwa mittels Patientenakten, Literatursuche und MRIBildern beurteilen muss, ob ein Meniskusriss bei einem Unfall oder aufgrund natürlicher Abnützung entstanden ist.»

\section{Die wiederentdeckte Pionierin}

In der Familie Heim war und ist man stolz auf die erste Schweizer Ärztin. Deren Ehemann Albert Heim aber Geologieprofessor an der ETH Zürich - war damals schweizweit bekannter. Er verfasste unter anderem geologische Gutachten im Zusammenhang mit Eisen-

Kürzlich in der Schweizerischen Ärztezeitung erschienene Beiträge über Marie Heim-Vögtlin:

- Naef J. Die erste Schweizer Ärztin - Dr. med. Marie Heim-Vögtlin.

Schweiz Ärztezeitung. 2016;97(9):315-7.

http://www.saez.ch/docs/saez/2016/09/de/SAEZ-04514.pdf

Müller VE. Die Anfänge des Frauenstudiums und ein Blick in die Praxis.

Schweiz Ärztezeitung. 2016;97(10):386-8.

http://www.saez.ch/docs/saez/2016/10/de/SAEZ-04395.pdf bahnbauprojekten wie dem Simplontunnel. In jüngster Zeit stellt Dominik Heim allerdings ein zunehmendes Interesse an der Person von Marie Heim-Vögtlin fest, vor allem im Zusammenhang mit Fragen der Gleichstellung.

Mit grosser Schaffenskraft setzte sich Marie Heim-Vögtlin neben ihrer Tätigkeit als Ärztin im 19. Jahrhundert auch für soziale Verbesserungen und beispielsweise das Frauenstimmrecht ein [1]. «Meine Urgrossmutter war eine sehr engagierte Ärztin, die ihrer Zeit voraus war», sagt Dominik Heim. Frauenstimmrecht und Frauen in der Medizin seien heute eine Selbstverständlichkeit, die Vereinbarkeit von Familie und Karriere allerdings nach wie vor schwierig - nicht nur in der Medizin. Dabei ist sich Dominik Heim bewusst, dass seine eigene berufliche Karriere nicht ohne die Hilfe seiner Frau möglich gewesen wäre, die sich mehrheitlich um die vier Kinder und den Haushalt kümmerte.

\section{Gesellschaftliche Verantwortung}

Seit der «Pensionierung» nutzt Dominik Heim seine Energie, um neben den drei Anstellungen noch mehr ehrenamtlich tätig zu sein. So organisierte er etwa für die Schweizerische Gesellschaft für Phlebologie (SGP) die Jahrestagung 2016 und hilft mit, Kongressprogramme der European Society for Trauma and Emergency Surgery (ESTES) zu gestalten. Dabei lässt er auch seine Begeisterung für Kunst, Film, Musik und Philosophie ins Programm der Veranstaltungen einfliessen. «Es tut Ärzten gut, wenn sie ihren Horizont erweitern", sagt er lachend. Den Leserinnen und Lesern der Schweizerischen Ärztezeitung sind seine Texte bekannt, in denen er oft Geschehnisse in Medizin und Gesellschaft mit Musikern und Filmen in Beziehung setzt.

"Mindestens bis 70-jährig will ich weiter so aktiv sein", sagt Heim. Als grosses Projekt steht etwa die Organisation des Kongresses des European Venous Forum im Juli 2019 in Zürich noch an. Sein ehrenamtliches Engagement macht ihm Spass, er betrachtet es aber auch als Teil einer gesellschaftlichen Verantwortung. Dabei möchte er auch Beispiel sein für die Berufskolleginnen und Berufskollegen. Sich eine bestimmte Zeit in einer ländlichen Region mit Ärztemangel niederlassen, den Gutachtermangel bei der SUVA lindern helfen oder Kongresse organisieren: "Zu tun gibt es genug.»

Literatur

1 vgl. Schweiz Ärztezeitung. 2016;97.

\section{Bildnachweise}

Porträt Dominik Heim: Adrian Ritter

Gruppenbild und Einzelbild mit Marie Heim-Vögtlin:

zVg von Dominik Heim 